\title{
International Bacteriological Code of Nomenclature
}

\author{
Edited by R. E. BUCHANAN, R. ST JOHN-BROOKS \\ AND R. S. BREED
}

Reprinted from the Journal of Bacteriology

The following Bacteriological Code of Nomenclature was developed by the Judicial Commission, approved and recommended by the Nomenclature Committee and adopted unanimously at the concluding Plenary Session of the International Association of Microbiologists at the fourth International Congress held in Copenhagen, Denmark, in July, 1947.

In 1948 it was published in the Journal of Bacteriology, 55, 287, but in view of its importance, it is reprinted here by permission of the Editor and Proprietors of that Journal.

\section{Chapter 1}

\section{GENERAL CONSIDERATIONS}

1. The progress of bacteriology can be furthered by a precise system of nomenclature which is properly integrated with the systems used by botanists and zoologists and accepted by the majority of bacteriologists in all countries. Bacteriological nomenclature considers bacteria, related organisms, and the viruses. Botanical and zoological codes provide for nomenclature of certain groups such as the yeasts and fungi, protozoa and algae. These are of such significance in the microbiological laboratory that provision is necessary in the bacteriological code for the consideration of special nomenclatural problems in these groups and for co-ordination of findings with zoologists and botanists.

2. The precepts on which this system of bacteriological nomenclature is based are divided into principles, rules, and recommendations.

The principles (Chapter 2 ) form the basis of the rules and recommendations.

The rules (Chapter 3 ) are designed (1) to make effective the principles given in Chapter 2, (2) to put the nomenclature of the past into order, and (3) to provide for that of the future. They are always retroactive; names or forms of nomenclature contrary to a rule (illegitimate names or forms) cannot be maintained.

The recommendations deal with subsidiary points, their object being to bring about greater uniformity and clearness, especially in future nomenclature; names or forms contrary to a recommendation cannot on that account be rejected, but they are not examples to be followed.

3. Provisions for emendation of rules, for special exceptions to rules, and for their interpretation in doubtful cases have been made through the establishment of a Nomenclature Committee for the International Association of Microbiologists and its Judicial Commission (Chapter 4). 


\section{Chapter 2}

\section{GENERAL PRINCIPLES}

Principle 1. The essential points in nomenclature are (1) to aim at fixity of names; (2) to avoid or to reject the use of forms and names which may cause error or ambiguity or throw science into confusion. Next in importance is the avoidance of all useless creation of names. Other considerations, such as absolute grammatical correctness, regularity or euphony of names, more or less prevailing custom, regard for persons, etc., notwithstanding their undeniable importance, are relatively accessory.

(See Rules 23, 24, 25, 26, 27; Recommendations 27a-i.)

Principle 2. In the absence of a relevant rule, or where the consequences of rules are doubtful, established custom must be followed. In doubtful cases a résumé in which all pertinent facts are outlined should be submitted to the Judicial Commission for an Opinion.

(See Recommendation 9c; Provision 4.)

Principle 3. Bacteriological nomenclature and botanical nomenclature are interdependent in the sense that the name of a bacterial group is to be rejected if it is a later homonym of the name of any plant group. Likewise nomenclature of bacteria and protozoa are interdependent; the name of a bacterial group is to be rejected if it is a later homonym of the name of a protozoan group. Bacteriological nomenclature is independent of zoological nomenclature (protozoology excepted); the name of a bacterial group is not to be rejected simply because it is identical with the name of a group in the animal kingdom.

(See Rule 24 (4).)

Principle 4. Scientific names of all groups are usually taken from Latin or Greek. When taken from any language other than Latin, or formed in an arbitrary manner, they are treated as if they were Latin. Latin terminations should be used so far as possible for new names.

(See Rules 1-8, 27, 28; Recommendations 5a, 6a, 6b, 6c, 8a, 27a-i.)

Principle 5. Nomenclature deals with (1) the terms which denote the rank of taxonomic groups (such as species, genus, family, order); (2) the names which are applied to the individual groups (such as Bacillus subtilis, Streptococcus, Spirillaceae, Spirochaetales).

(See Principle 7; Rules 1-8; Recommendations 6a-c, 8a, 24a.)

Principle 6. The rules and recommendations of bacteriological nomenclature apply to all bacteria, recent and fossil, with certain distinctly specified exceptions.

(See General Considerations 1; Principle 9; Provisions 2-4.)

Principle 7. The terms which denote the rank of taxonomic groups are defined as follows:

(a) Every individual belongs to a species, every species to a genus, every genus to a family, every family to an order, every order to a class, every class to a division. In some families the rank tribe may be distinguished.

(See Principle 5; Rules 1-8; Recommendations 5a, 6a-c.) 


\section{R. E. Buchanan, R. St John-Brooks and R. S. Breed}

(b) In many species, subspecies or varieties are distinguished; in some cases subdivisions of a species such as strains, groups, serotypes, variants, phases, and others may be recognized. In some genera, subgenera may be distinguished.

(See Rules 6, 7; Recommendations $6 a-c, 8 a$.)

(c) If a greater number of intermediate categories (ranks) are required, the terms for these subdivisions are made by adding the prefix 'sub-' to the terms denoting the ranks. Thus subfamily denotes a rank between a family and a tribe, subtribe a rank between a tribe and a genus, etc. The classification of subordinate categories (ranks) may thus be carried for the bacteria in the following order.

1. Division (Divisio)

2. Subdivision (Subdivisio)

3. Class (Classis)

4. Subclass (Subclassis)

5. Order $($ Ordo $)$

6. Suborder (Subordo)

7. Family (Familia)

8. Subfamily (Subfamilia)
9. Tribe (Tribus)

10. Subtribe (Subtribus)

i1. Genus (Genus)

12. Subgenus (Subgenus)

13. Species (Species)

14. Subspecies (Subspecies)

15. Variety (Varietas)

16. Individual (Individuum)

(d) The definition of each of these categories (ranks) varies, up to a certain point, according to individual opinion and the state of the science; but their relative order, sanctioned by custom, must not be altered. No classification is admissible which contains such alteration.

Principle 8. The primary purpose of giving a name to a taxonomic group is not to indicate the characters or the history of the group, but to supply a means of referring to it.

(See Rule 23.)

Principle 9. Each group with a given circumscription, position, and rank can bear only one valid name, the earliest that is in accordance with the Rules of Nomenclature. Provisions may be made for certain exceptions.

(See Principle 6; Rules 24-26; Provisions 2, 3, 4.)

Note. In subgenera, genera, and groups of higher rank, the valid name is the earliest name published, provided that this is in conformity with the Rules of Nomenclature.

In species the valid name is the binary and in subspecies the ternary combination containing the earliest epithet published, provided that this combination is in conformity to the Rules of Nomenclature.

Principle 10. Bacteriologists are urged not to change a name (or combination of names) without serious motives, based either on more profound knowledge of facts or on the necessity of giving up a nomenclature that is contrary to the Rules.

Principle 11. The application of names of taxonomic groups is determined by means of nomenclatural types. A nomenclatural type is that constituent element of a group to which the name of the group is permanently attached, whether as an accepted name or as a synonym. The name of a group must be changed if the type bearing that name is excluded. 
The type of a generic name is a species, that of the name of a species or subspecies (variety) is usually an authentic culture, a specimen, or a preparation. In some species, however, the type is a description or a figure given by a previous author. Where permanent preservation of a culture, a specimen, or preparation is impossible, the application of the name of a species or subdivision of a species is determined by means of the original description or figure.

(See Rule 9; Recommendations 9a-d.)

Note. The nomenclatural type is not necessarily the most typical or representative element of a group; it is merely that element with which the name of the group is permanently associated.

(Examples: The type of the name Bacillus is the species Bacillus subtilis. The type of Pseudomonas suaveolens Soppeland is the culture designated and deposited by the author as the type culture in the American Type Culture Collection. The type of Actinomyces cameli (Mason) Ford consists of the description and illustration ( $J$. trop. med. (Ther.), 1919, 32, 34) as no cultures are available.)

Principle 12. A name of a taxonomic group has no status under the Rules, and no claim to recognition by bacteriologists, unless it is validly published.

(See Rules 10-14; Recommendations 12a-c.)

Chapter 3

\section{RULES OF NOMENCLATURE WITH RECOMMENDATIONS}

\section{Section 1. Naming of groups of various ranks}

Rule 1. Names of divisions, subdivisions, classes, subclasses, orders, suborders, families, subfamilies, tribes and subtribes are taken either from their chief characters or from a taxonomic unit of the next lower rank.

Rule 2. The names of all ranks higher than the genus are written in the plural number.

Rule 3. Names of divisions, subdivisions, classes, and subclasses are words of Greek or Latin origin.

(See Principles 4, 5, 7; Rules 24, 25.)

Rule 4. Names of orders, suborders, families, subfamilies, tribes and subtribes are also words of Greek or Latin origin or Latinized words, each with a suffix to indicate its taxonomic rank. The suffix for orders is -ales, for suborders ineae, for families -aceae, for subfamilies -oideae, for tribes -eae, and for subtribes -inae.

(See Principles 4, 5, 7; Rules 22, 24, 25.)

Rule 5. Names of genera and of subgenera are substantives (or adjectives used as substantives) in the singular number and written with an initial capital. These names may be taken from any source whatever and may even be composed in an arbitrary manner. They are treated as Latin substantives. Generic names and subgeneric names are subject to the same rules and recommendations and, from a nomenclatural standpoint, they are co-ordinate.

(See Principles 4, 5, 7.)

Examples: Bacillus, Pasteuria, Brucella, Alcaligenes, Fusiformis.

If a genus is divided into subgenera, one of the subgenera (that which includes the type of the genus) should bear the same name as the genus.

(See Rules 9, 19, 20, 27, 28; Recommendations $9 a-c, 19 a, 17 i$.) 


\section{$448 \quad R$. E. Buchanan, R. St John-Brooks and R. S. Breed}

Example: If the genus Bacillus is divided into two or more subgenera, the subgenus which includes the type species Bacillus subtilis should bear the subgeneric name Bacillus.

Recommendation 5a. Bacteriologists who are forming new generic or subgeneric names should attend to the following recommendations:

(1) Not to make names very long or difficult to pronounce.

(2) To take names that have an agreeable form readily adaptable to the Latin tongue.

(3) Not to dedicate genera to persons quite unconnected with bacteriology or at least with natural science nor to persons quite unknown.

(4) To avoid adjectives used as nouns.

(5) Not to make names by combining words from different languages (nomina hybrida).

(6) To give a feminine form to all personal generic names, whether they commemorate a man or a woman.

(See Principles 4, 7; Rule 27 ; Recommendations $27 a-i$ for orthography and gender of generic names.)

Rule 6. Names of species are binary combinations consisting of the name of the genus followed by a single specific epithet.* If an epithet consists of two or more words, these must either be united or joined by hyphens. Specific epithets are:

(a) Adjectives, which must agree grammatically with the generic name. Examples: Bacillus subtilis, Micrococcus aureus, Clostridium botulinum.

(b) Substantives, in the nominative, in apposition with the generic name. Examples: Flavobacterium ceramicola, Vibrio comma, Pseudomonas conjac, Phytomonas holcicola.

(c) Substantives in the genitive. Examples: Phytomonas vascularum, Aerobacter cloacae, Rhizobium leguminosarum, Brucella abortus, Acetobacter aceti, Salmonella anatis, Borrelia kochii.

Within the same genus, no two species names bear the same specific epithet.

(See Principles 4, 5, 7; Rule 27; and Recommendations $27 a-i$ for orthography and gender of specific names.)

Recommendation $6 a$. When it is desired to indicate the name of a subgenus in connection with the generic name and specific epithet, the name of the subgenus may be placed in parentheses between the two.

Example: Lactobacillus (Thermobacterium) caucasicus.

(See Principles 4, 5, 7.)

Recommendation $6 b$. In forming specific epithets bacteriologists should attend to the following recommendations:

(1) To choose a specific epithet which, in general, gives some indication of the

* The term 'epithet' as here used implies a single descriptive word or a single descriptive phrase.

Examples: The Latin word aureus (golden) is a single descriptive adjective or epithet, and the species name Micrococcus aureus would be in correct form. The phrase lac acidum (sour milk) is a single epithet, and the species name Streptococcus lactis-acidi (or lactisacidi) (Streptococcus of sour milk) is in correct form. Care should be used not to regard a sequence of unrelated words as a single epithet. The species name Bacillus aureus lactis (the golden bacillus of milk) would be an invalid trinomial; there are two specific epithets. The name cannot be validated by hyphenating the two words as Bacillus aureus-lactis; there are still two unrelated epithets. If the two words are combined as in the specific name Bacillus aurei-lactis, the meaning is completely changed to Bacillus of golden milk; the species name is in correct form, but the meaning is nonsensical unless applied to an organism which changes the colour of the milk to golden. 
appearance, the characters, the origin, the history, or the properties of the species. If taken from the name of a person, it usually recalls the name of the one who discovered or described it, or was in some way concerned with it.

Examples: Micrococcus aureus, Clostridium pasteurianum, Phytomonas campestris, Bacillus viscosus, Kurthia zopfii.

(2) To avoid those which are very long and difficult to pronounce.

(3) To avoid those which express a character common to all or nearly all the species of a genus.

Example: Micrococcus sphericus.

(4) To avoid using the names of little-known or very restricted localities, unless the species is quite local.

(5) To avoid, in the same genus, epithets which are very much alike, especially those which differ only in their last letters.

(6) Not to adopt unpublished names found in authors' notes, attributing them to their authors, unless these have approved publication.

(See Principles 4, 5, 7.)

Recommendation $6 c$. Names of men and women and also of countries and localities used as specific epithets may be substantives in the genitive (welchii) or adjectives (pasteurianum, japonicum). It will be well, in the future, to avoid the use of the genitive and the adjectival form of the same epithet to designate two different species of the same genus.

(See Principles 4, 5, 7.)

Rule 7. Names of subspecies (varieties) are ternary combinations consisting of the name of the genus followed by the specific and subspecific epithets in order.

Example: Escherichia coli subsp. communior (Topley and Wilson) Breed et al. or Escherichia coli var. communior, or Escherichia coli communior. This does not justify the name Bacillus fluorescens liquefaciens, as this name was originally proposed as a trinomial name for a species, and not for a subspecies or a variety.

Epithets of subspecies (varieties) are formed like those of species; when adjectival in form and not used as substantives they agree in gender with the generic name.

Neither within the same species nor within the same genus may two subspecies bear the same subspecific epithet.

If the species is divided into subspecies, the subspecific epithet of the subspecies containing the type of the species shall be the same as that of the species.

(See Principles 4, 5, 7.)

Example: If Micrococcus aureus is divided into two or more subspecies, one (that containing the type) should be designated Micrococcus aureus subsp. aureus.

Rule 8. Subdivisions of species (other than subspecies (varieties)) are given vernacular names or designated by numerals or letters or, in special cases, are given names in Latin form.

(See Principles 4, 5, 7.)

Recommendation $8 a$. Authors of names of subdivisions of species of bacteria which are not treated as subspecies (varieties) should attend to the following recommendations and definitions:

(1) A strain is a pure culture of bacteria made up of the descendants of a single isolation. It is frequently designated by the name of the individual responsible for its isolation, as Corynebacterium diphtheriae strain Park-Williams. It may also be 
designated by the locality or by a number or some similar laboratory distinguishing mark. Strain may also be used to designate cultures of bacteria which correspond to cultivated 'varieties' of higher plants in having some special economic significance. Such are frequently names from the laboratory or factory where isolated, as Acetobacter aceti strain Carlsberg.

(2) Type is a term which has frequently been used to designate a subdivision of a species, particularly in cases where the differentiating characters are regarded as insufficient to justify the erection of a subspecies or variety. Types are often differentiated on the basis of antigenic characteristics. Type is sometimes used to designate a physiological or morphological variant. In view of the use of the word 'type' in a different sense as defined in Principle 11, it is suggested that the terms serotype (or serological type), biotype (or physiological type) and morphotype (or morphological type) may appropriately be substituted for type as a designation of a subdivision of a species.

(3) The term group in bacteriology should be used with great eare so as to avoid ambiguity. It is employed popularly to designate various organisms with common characteristics (i.e., 'Coli-aerogenes Group') and, in a restricted sense, in antigenic analysis for designating species or subgenera (e.g. Streptococcus, group A, Lancefield), or varieties or subspecies (e.g. Neisseria intracellularis, group I, Scott). It is suggested that the term group be reserved for primary serological divisions and designated by capital letters. Any serological subdivisions within the group should be designated as types and distinguished by Arabic numerals (e.g. Bacterium pseudotuberculosis-rodentium group A, type 1, Schütze).*

(4) The designation phase should be restricted to use for bacteria showing certain alternative immunologic characteristics, and particularly for the 'specific phase' or 'nonspecific phase' of Andrewes as recorded for the genus Salmonella.

Example: Salmonella enteritidis specific phase.

(5) A form (forma) or special form (forma specialis) is a subdivision of a species of a parasitic microorganism distinguished primarily by adaptation to a particular host. It is named preferably by giving it the scientific name of the host. This is written preferably in the genitive.

Example: Rhizobium phaseoli forma phaseoli multiflori or Rhizobium phaseoli f. sp. phaseoli multiflori.

(6) A variant is an organism showing some variation in some character from the parent culture. Frequently variants result by mutation. If sufficiently distinct and stable, the variant may even be regarded and named as a subspecies or variety. Example of variant: the progeny of a colour sector in a pigmented colony, or the progeny of secondary colonies as lactose-fermenting mutants in colonies of glucosefermenting bacteria.

Example: Shigella sonnei lactose-positive variant.

(7) A stage or state is the name given to the Rough, Smooth, Mucoid, and similar variants which arise from colonies of many species of bacteria. These are regarded as alternating stages which are generally reversible and indeed by some authors as

* It may be urged that if specific names are substituted for group letters at present employed (as strictly speaking they should be) the whole serological concept of the genus is obscured, and it would be difficult to get serologists, working in many of the various fields, to assent to an action that they might consider retrograde. But this procedure has been accepted by the Salmonella Subcommittee in the case of the genus Salmonella. However, all workers in this field are familiar with the Kauffmann-White schema which clearly shows the antigenic relations within the genus concept. A somewhat similar procedure might be employed, for example, in the case of the streptococci, i.e. an approved schema drawn up showing the antigenic relationships within the various groups which should be given specific rank with names consistent, so far as possible, with the laws of priority. It is suggested that the Salmonella Subcommittee in this regard has made a sincere effort to reconcile the traditions of the past with the present practical necessity of stressing serological relationships, where they exist. 
part of a pleomorphic life cycle. They may be designated by some vernacular descriptive name.

Example: Bacillus subtilis Rough stage.

(See Principles 4, 5, 7b.)

\section{Section 2. Designation of nomenclatural types}

Rule 9. For each valid name of each taxonomic group there should be designated a type; that is for each species or subspecies a type culture, specimen, or description, for each genus a type species (genotype).

(See Principle 11; Rule 5.)

Recommendation $9 a$. When publishing names of new taxonomic groups, authors should indicate carefully the subdivision which is the type of the new name: The type species (genotype) in a genus, the type subspecies or variety in a species in which these subdivisions are recognized, the type specimen, preparation, or description in a species. This type determines the application of the name in the event of the taxonomic group being subsequently divided. When describing new species, varieties, or forms of parasitic bacteria, the host of the type should be indicated.

(See Principle 11; Rule 5.)

Recommendation $9 b$. When revising a genus for which no genotype has been designated, an author should state which species he accepts as the nomenclatural type.

(See Principle 11; Rule 5.)

Recommendation $9 c$. In selecting a nomenclatural type (genotype) for a genus of bacteria, bacteriologists should, when possible, choose a species that will fix the generic name as it is now commonly applied.

(See Principles 2,$11 ;$ Rule 5.)

Recommendation $9 d$. The utmost importance should be given to the preservation of the original ('type') material on which the description of the new group is based. The original account should state where this material is to be found. When a new species or subspecies of bacterium is described, if the organism is one which may be maintained in pure culture, an authentic culture labelled as 'type' should be deposited with one of the recognized national or international type culture collections. The national or international type culture depositories recognized are designated by the action of the International Committee of Nomenclature. These recognized in $\mathbf{1 9 3 9}$ are the National Collection of Type Cultures of Microorganisms maintained in London, England,* and the American Type Culture Collection, Washington, D.C. Inasmuch as the type of a bacterial species is frequently the published description and drawings, these should be as complete as possible.

Note. It should be borne in mind that morphological, biochemical and antigenic changes, and also loss of virulence, may take place as the result of repeated subculture in the collection. This can to some extent be obviated by drying cultures in high vacuum under optimal conditions and storing them for future reference.

(See Principle 11.)

\section{Section 3. Publication of names}

Rule 10. Legitimate bacteriological nomenclature begins with Linnaeus' Species Plantarum, ed. 1, 1753. $\dagger$

(See Principle 12.)

Rule 11. Publication is effected, under these Rules, by sale or distribution of printed matter to the general public or to bacteriological institutions. No

* Present address : Central Public Health Laboratory, Colindale Avenue, London, N.W. 9. $\dagger$ Fixed by action of the First International Congress of Microbiology in Plenary Session, Paris, 1930 (Proceedings, Part 2, p. 527). 


\section{2 \\ R. E. Buchanan, R. St John-Brooks and R. S. Breed}

other kind of publication is accepted as effective (effective publication); communication of new names at a public meeting, or the placing of names in collections, does not constitute effective publication.

Where reprints or separates from periodicals or other works are placed on sale or issued in advance, the date on the separate is accepted as the date of effective publication.

The date of acceptance of an article for publication as given in a publication does not indicate the effective date of publication and has no significance in determination of priority of publication of names.

(See Principle 12; Rule 12.)

Rule 12. A name of a taxonomic group is not validly published unless it is both (1) effectively published (See Rule 11), and (2) accompanied by a description of the group or by a reference to a previously and effectively published description of it.

The words 'valid' or 'validly published' as used in these Rules mean 'with standing in nomenclature', and the words 'invalid' or 'not validly published' mean 'without standing in nomenclature'.

Mention of a name on a label on a culture or preparation of bacteria in a collection without printed or autographed description does not constitute valid publication of that name.

A name of a taxonomic group is validly published only if it has been definitely accepted by the author who published it. A name proposed provisionally (nomen provisorium) in anticipation of the eventual acceptation of the group, or of the circumscription, position, or rank given to a group, or mentioned only incidentally is not validly published.

Example: Beijerinck (Arch. neerl. d. sc. exactes, 1903, Sec. 2, 8, 217) mentioned in a footnote to his article describing and naming the genus Azotobacter that Parachromatium might be a suitable name. It was never formally proposed or adopted, and has no standing in nomenclature.

A name of a taxonomic group is not validly published when it is merely cited as a synonym.

Example: Trevisan (Rendiconti Real. Ist. Lombard. d. Sci. e Lett., Ser. 2, 1879, 12, 144) cited Malleomyces equestris Hallier as a synonym of Micrococcus equestris, which he regarded as the causal organism of glanders. Inasmuch as all of Hallier's species were based upon mixed cultures and his names invalid, this incidental citation as synonym by Trevisan does not validate the name. Malleomyces must date as a generic name from its proposal by Pribram in 1933 (Klassification des Schizomyceten, p. 93).

A group is not characterized, and the publication of its name is not validated merely by mention of the subordinate groups included in it: thus, the publication of the name of an order is not validated by mention of the included families; that of a family is not validated by mention of the included genera; that of a genus is not validated by mention of the included species.

The date of a name or of an epithet is that of its valid publication. For purposes of priority, however, only legitimate names and epithets published in legitimate combinations are taken into consideration. In the absence of 
proof to the contrary, the date given in the work containing the name or epithet must be regarded as correct.

(See Principle 12; Rule 27, Note 1.)

Example: Chondromyces crocatus Berkeley \& Curtis 1857 (in Berkeley, Introduction to Cryptogamic Botany, p. 313) is a name appended to an illustration with description. The description was published later (Berkeley, Grevillea, 1874, 3, 64) and valid publication was of the later date.

Recommendation $12 a$. When publishing names of new groups of bacteria in works written in a language unfamiliar to the majority of workers in bacteriology, it is recommended that the authors publish simultaneously the diagnoses in a more familiar language.

(See Principle 12.)

Recommendation $12 b$. Authors should indicate precisely the date of their works. In the case of a work appearing in parts, the last published sheet of the volume should indicate the precise dates on which the different fascicles or parts of the volume were published as well as the number of pages in each.

(See Principle 12.)

Recommendation 12c. When works are published in periodicals, the author should require the publisher to indicate on the separates or reprints the date (year and month, if possible the day) of publication and also the title of the periodical from which the work is extracted. Separates or reprints should always bear pagination of the periodical of which they form a part; if desired, they may also bear a special pagination.

(See Principle 12.)

Rule 13. A name of a genus is not validly published unless it is accompanied (1) by a description of the genus, or (2) by the citation of a previously and effectively published description of the genus under another name; or (3) by a reference to a previously and effectively published description of the genus as a subgenus, or other subdivision of a genus.

The name of a monotypic new genus based on a new species is validated by the provision of a combined generic and specific description.

(See Principle 12.)

Examples of validly published generic names: Bacillus Cohn 1872, Pasteurella Trevisan 1885, Sarcina Goodsir 1842, Polyangium Link 1809.

Rule 14. The name of a species or a subspecies (variety) is not validly published unless it is accompanied (1) by a description of the group; or (2) by the citation of a previously and effectively published description of the group under another name.

(See Principle 12.)

Example of validly published name of species: Bacillus subtilis Cohn 1872.

\section{Section 4. Citation of authors and names}

Rule 15. For the indication of the name (unitary, binary, or ternary) of a group to be accurate and complete, and in order that the date may be readily verified, it is necessary to cite the author who first published the name in question.

Examples: Plocamobacteriales Pribram (or Pribram 1933), Proteus Hauser (or Hauser 1885), Serratia marcescens Bizio (or Bizio 1823). 


\section{$454 \quad R$. E. Buchanan, R. St John-Brooks and R. S. Breed}

An alteration of the diagnostic characters or of the circumscription of a group without exclusion of the type does not warrant the citation of an author other than the one who first published the name. When the changes have been considerable, an indication of their nature and of the author responsible for the change is added, as, em. (emendavit) or mutatis charact., or pro parte, or excl. gen., excl. sp., excl. var., or some other abridged indication.

Example: Bacillus Cohn em. Migula.

When a name of a taxonomic group has been proposed but not published by one author, and is subsequently validly published and ascribed to him (or her) by another author who supplied the description, the name of the latter author must be appended to the citation with the connecting word $e x$. If it is desirable or necessary to abbreviate such a citation, the name of the publishing author, being the more important, must be retained.

Example: Salmonella dar-es-salaam Schütze ex. Brown, Duncan and Henry.

When a name and description by one author are published by another author, the word apud is used to connect the names of the two authors, except where the name of the second author forms part of the title of a book or periodical, in which case the connecting word in is used instead.

Rule 16. When a genus, a subgenus, a species, or a subspecies (variety) is altered in rank but retains its name or epithet, the original author must be cited in parentheses, followed by the name of the author who effected the alteration. The same holds when a subgenus, a species, or a subspecies (variety) is transferred to another genus or species with or without alteration of rank.

Example: Spirochaete pallida Schaudinn and Hoffman becomes Treponema pallidum (Schaudinn and Hoffman) Schaudinn.

Recommendation 16 . When citing a name published as a synonym, the words 'as synonym' or 'pro synon.' should be added to the citation.

When an author publishes as a synonym a manuscript name of another author, the word $e x$ should be used to connect the names of the two authors.

Recommendation $16 b$. When eiting in synonymy a name invalidated by an earlier homonym, the citation should be followed by the name of the author of the earlier homonym preceded by the word 'non', preferably with the date of publication added. In some instances it will be advisable to cite also any later homonym or homonyms.

Example: Myxococcus Gonnerman 1907 non Thaxter 1892.

\section{Section 5. Changes in names as a result of segregation or union of groups or change in rank of groups}

Rule 17. An alteration of the diagnostic characters, or of the circumscription of a group, does not warrant a change in its name except insofar as this may be necessitated (1) by transference of the group or (2) by a change of its rank.

When a genus is divided into two or more genera, the generic name must be retained for one of them, or (if it has not been retained) must be re-established. When a particular species was originally designated as the type, the generic name must be retained for the genus including that species. When no type was designated, a type must be chosen. 
Example: Donker (1926) divided the genus Bacillus into Bacillus and Aërobacillus, retaining Bacillus for the genus containing the type species Bacillus subtilis.

The same rule is applied when a subgenus is divided into two or more subgenera.

Rule 18. When a species is divided into two or more species, the specific epithet must be retained for one of them, or (if it has not been retained) must be re-established. When a particular specimen was originally designated as the type, the specific epithet must be retained for the species including that specimen. When no type was designated, a type must be chosen according to the regulations given.

The same rule applies to subspecies (varieties); for example, to a subspecies (variety) divided into two or more subspecies (varieties).

Example: When Rhizobium leguminosarum Frank was divided into several species, all symbiotic on the roots of leguminous plants, the name $\boldsymbol{R}$. leguminosarum was correctly retained for one of them by Fred.

When a species is transferred to another genus (or placed under another generic name for the same genus), without change of rank, the specific epithet must be retained or (if it has not been retained) must be re-established unless one of the following obstacles exists: (1) the resulting binary name is a later homonym or tautonym or (2) there is available an earlier validly published specific epithet.

When the specific epithet, on transference to another generic name, has been applied erroneously in its new position to a different species, the new combination must be retained for the organism on which the epithet was originally based.

Rule 19. When two or more groups of the same rank are united, the oldest legitimate name or (in species and their subdivisions) the oldest legitimate epithet is retained. If the names or epithets are of the same date, the author who unites the group has the right of choosing one of them. The author who first adopts one of them, definitely treating another as a synonym or referring it to a subordinate group, must be followed.

(See Rule 5.)

Recommendation $19 a$. Authors who have to choose between two generic names should note the following recommendations:

(1) Of two names of the same date to prefer the one which was first accompanied by the description of a species.

(2) Of two names of the same date, both accompanied by descriptions of species, to prefer the one which, when the author made his choice, included the larger number of species.

(3) In cases of equality from these various points of view to prefer the more correct and appropriate name.

(See Rule 5.)

Rule 20. When several genera are united as subgenera under one generic name, the subgenus including the type of the generic name used must bear that name unaltered.

(See Rule 5.) 
Rule 21. When several species are united as subspecies or varieties under one specific name, the subdivision which included the type of the specific epithet used must be designated by the same epithet unaltered.

Rule 22. (1) When a subtribe becomes a tribe, when a tribe becomes a subfamily, when a subfamily becomes a family, etc., or when the inverse changes occur, the stem of the name should not be altered but only the termination (-inae, -eae, -oideae, -aceae, -ineae, -ales, etc.).

(2) When a subgenus becomes a genus, or the inverse changes occur, the original name should be retained.

(3) When a subdivision of a species becomes a species, or the inverse change occurs, the original epithet should be retained unless the resulting combination is rejected under Section 6 .

(See Rules 3, 4.)

\section{Section 6. Rejection and replacement of names}

Rule 23. A name or epithet must not be rejected, changed, or modified merely because it is badly chosen or disagreeable, or because another is preferable or better known.

(See Principles 1, 8, 10.)

Rule 24. A name must be rejected if it is illegitimate, i.e. if it is contrary to a rule. The publication of an epithet in an illegitimate combination must not be taken into consideration for purposes of priority.

(See Principle 1 Rules 1-4.)

A name of a taxonomic group is illegitimate in the following cases:

(1) If it was nomenclaturally superfluous when published, i.c. if the group to which it was applied, as circumscribed by its author, included the type of a name which the author ought to have adopted under one or more of the Rules.

Example: Dicrobactrum Enderlein 1917 was superfluous because of the previous publication of Serratia Bizio 1823.

(2) If it is a binary or ternary name published in contravention of Principle 9 and $R$ ules $\mathbf{1 7 - 2 3}$, i.e. if its author did not adopt the earliest legitimate epithet available for the group with its particular circumscription, position, and rank.

(3) If its specific epithet must be rejected under Rule $\mathbf{2 5}$.

(4) If it is a later homonym of a genus of bacteria, of a genus of plants, or of a genus of protozoa; that is, if it duplicates a name previously and validly published for a group of the same rank based on a different type. Even if the earlier homonym is illegitimate, or is generally treated as a synonym on taxonomic grounds, the later homonym must be rejected. When an author simultaneously publishes the same new name for more than one group, the first author who adopts one of them, or substitutes another name for one of them, must be followed.

Recommendation 24a. Authors should avoid introducing into bacteriology as generic names such names as are in use in zoology.

(See Principle 5.)

Note. Mere orthographic variants of the same name are treated as homonyms when they are based on different types.

(See Rule 28.) 
(5) If, owing to a segregation, it is used with different meanings, and so becomes a permanent source of confusion or error. A list of names to be abandoned for this reason will be included under nomina rejicienda.

(See Principle 3; Provision 3.)

(6) If its application is uncertain (nomen dubium). A list of names to be abandoned for this reason will be included under nomina rejicienda.

(Sec Provision 3.)

(7) If the characterization of the group was based upon an impure or mixed culture. A list of names to be abandoned for this reason (nomina confusa) will be included under nomina rejicienda.

(See Provision 3.)

Examples: The characters of the genus Malleomyces Hallier 1870 were derived from various fungi and bacteria erroneously supposed to be growth forms of a single organism. The name Salmonella tokio Aoki was based upon a mixed culture.

(8) If it was based upon an abnormality.

Example: An eroded colony of Shigella dysenteriae due to bacteriophage action would be such an abnormality.

Rule 25. Specific epithets are illegitimate in the following special cases and must be rejected.

(1) When they are merely words not intended as names.

(2) When they are merely ordinal adjectives being used for enumeration.

(3) When they exactly repeat the generic name (Tautonym).

(See Principles 1, 9; Rules 1, 2.)

Rule 26. The name or epithet to be rejected according to Rules $\mathbf{2 3 - 2 5}$ is replaced by the oldest legitimate name, or (in a combination) by the oldest legitimate epithet which will be, in the new position, in accordance with the Rules. If none exists, a new name or epithet must be chosen. Where a new epithet is required, an author may, if he wishes, adopt an epithet previously given to the group in an illegitimate combination, if there is no obstacle to its employment in the new position or sense.

(See Principles 1, 9.)

\section{Section 7. Orthography and gender of names}

Rule 27. The original spelling of a name or epithet must be retained, except in the case of a typographical error, or of a clearly unintentional orthographic error. When the difference between two generic names lies in the termination, these names must be regarded as distinct, even though differing by one letter only. This does not apply to mere orthographic variants of the same name.

(See Principles 1, 4, 9; Rules 5, 6 (c); Recommendation 5a.)

Example: Streptococcus erysipelatos and $S$. erysipelatis are mere orthographic variants of the same name. Erysipelatos is the strict transliteration of the Greek genitive; erysipelatis is the form of the more usual and preferable transliteration into Latin form.

Note 1. The words 'original spelling' in this Article mean the spelling employed when the name was validly published.

(See Rules 1, 2.) 
Note 2. The use of a wrong connecting vowel or vowels (or the omission of a connecting vowel) in a specific epithet, or in the name of a genus is treated as an unintentional orthographic error which may be corrected.

Note 3. In deciding whether two or more slightly different names should be treated as distinct or as orthographic variants, the essential consideration is whether they may be confused with one another or not. If there is a serious risk of confusion they should be treated as orthographic variants. Doubtful cases should be referred to the Judicial Commission for an Opinion.

Note 4. Specific and other epithets and names of Greek origin differing merely by having Greek and Latin terminations respectively are orthographic variants. Epithets bearing the same meaning and differing only slightly in form are considered as orthographic variants. The genitive and adjectival forms of a personal name are, however, treated as different epithets.

Example: Hormodendron and Hormodendrum; the strict transliteration of the Greek neuter ending is -on. The usual and preferable transliteration into the Latin is -um.

The liberty of correcting a name must be used with reserve, especially if the change affects the first syllable, and above all the first letter of the name.

Recommendation $27 \mathrm{a}$. When a new name is derived from a Greek work containing the spiritus asper (rough breathing), this should be transeribed as the letter $h$.

(See Principles 1, 4; Recommendation 5a; Rule $6(c)$.)

Recommendation $27 b$. For scientific names it is advisable to use another font than that used for the remainder of the text, or to space the letters, or to use similar device appropriate to the text.

Example: 'The disease anthrax is caused by Bacillus anthracis Koch.' Typewritten scientific names should be underlined.

(See Principles 1, 4; Recommendation 5a; Rule $6(c)$.

Recommendation $27 c$. When a new name for a genus or subgenus is taken from the name of a person, it should be formed in the following manner:

(1) When the name of the person ends in a vowel the letter $a$ is added (thus, Gaffkya after Gaffky; Noguchia after Noguchi; Serratia after Serrati), except when the name already ends in $a$, when $e a$ is added (e.g. Collaea after Colla).

(2) When the name of a person ends in a consonant the letters $i a$ are added (e.g. Escherichia after Escherich, Erwinia after Erwin F. Smith, Pasteuria after Pasteur), except when the name ends in $e r$, when $a$ is added (e.g. Kernera after Kerner).

(3) Names may be formed by use of a prefix or a suffix, or modified by anagram or abbreviation. In these cases they count as different words from the original name.

In many cases the names of bacterial genera are formed from the names of persons by the addition of a diminutive ending. The most common modern Latin convention is to add one of the endings -ellus, $a$, um, preferably -ella to conform to Recommendation 5a. In some few cases one of the endings -illus, $a$, um has been added.

(See Principles, 1, 4; Recommendation 5a; Rule $6($ c).)

(4) The syllables which are not modified by these endings retain their original spelling, even with the consonants $k$ and $w$ or with the groupings of vowels which were not used in classical Latin. Letters foreign to botanical Latin should be transeribed and diacritic signs suppressed. The Germanic $\ddot{a}, \ddot{o}, \ddot{u}$ become $a e, o e, u e$; the French $\dot{e}$, $\dot{e}$, and $\hat{e}$ become generally $e$. In works in which diphthongs are not represented by special type, the diaeresis sign should be used where required, e.g. Aerrobacillus not Aerobacillus.

Recommendation $27 d$. A new specific or subspecific (varietal) epithet taken from the name of a man may assume either a substantival or an adjectival form. The syllables which are not modified by these endings retain their original spelling, even with the consonants $k$ or $w$ or with the groupings of vowels which were not used in classical Latin. Letters foreign to botanical Latin should be transcribed and 
diacritic signs suppressed. The Germanic $\ddot{a}, \ddot{o}, \ddot{u}$ become $a e, o e, u e$. The French $\dot{e}, \grave{e}, \hat{e}$ become generally $e$.

When the epithet is a substantive, it is formed in the following manner:

(1) When the name of the person ends in a vowel, the letter $i$ is added (thus, sonne $i$ from Sonne) except when the name ends in $a$, when $e$ is added (thus, balansae from Balansa).

(2) When the name ends in a consonant, the letters $i i$ are added (thus, welchii from Welch) except when the name ends in -er, when $i$ is given (thus, barkeri from Barker).

When the epithet is an adjective, it is formed by the addition of an appropriate ending (thus, pasteurianus, $a$, um from Pasteur).

(See Principles 1, 4; Recommendations 5a; Rule $6(c)$.)

Recommendation 27 . The same provisions apply to epithets formed from the names of women. When these have a substantival form they are given a feminine termination. ('Thus, Cytophaga krzemieniewskae.)

(See Principles 1, 4; Recommendation $5 a$; Rule $6(c)$.)

Recommendation $27 f$. New specific (or other) epithets should be written in conformity with the original spelling of the words from which they are derived and in accordance with the rules of Latin and latinization.

Examples: silvestris (not sylvestris), sinensis (not chinensis).

(See Principles 1, 4; Recommendation 5a; Rule $6(c)$.)

Recommendation $27 \mathrm{~g}$. Specific epithets, even those derived from names of persons, should not be capitalized.

(See Principles 1, 4; Recommendation 5a; Rule $6(c)$.)

Recommendation $27 \mathrm{~h}$. In the formation of names or epithets composed of two or several roots taken from Latin or Greek, the vowel placed between the two roots becomes a connecting vowel, in Latin usually $i$, in Greek usually 0 . When the second root begins with a vowel and euphony requires, the connecting vowel should be eliminated (e.g. lepidantha). The connecting vowels $a e$ should be retained only where this is required for etymological reasons (e.g. caricaeformis from Carica, in order to avoid confusion with cariciformis from Carex). In certain compounds of Greek words, no connecting vowel is required, e.g. brachycarpus and glycyphyllus.

(See Principles 1, 4; Recommendation 5a; Rule $6(c)$.)

Recommendation 27i. Authors should give the etymology of new generic names, and also of new epithets when the meaning of these is not obvious.

(See Principles 1, 4; Rule 5; Recommendation 5a; Rule $6(c)$.)

Rule 28. The gender of generic names is governed by the following regulations:

(1) A Greek or Latin word adopted as a generic name retains its classical gender. In cases where the classical gender varies the author has the right of choice between the alternative genders. In doubtful cases general usage should be followed.

(2) Generic names which are modern compounds formed from two or more Greek or Latin words take the gender of the last. If the ending is altered, however, the gender will follow it.

Example: Spirochaete is feminine because the Greek noun chaete ( $\chi$ a r $\eta)$ is feminine. However, if a name Spirochaetum were proposed it would be neuter.

(3) Arbitrarily formed generic names or vernacular names used as generic names take the gender assigned to them by their authors. Where the original author has failed to indicate the gender, the next subsequent author has the right of choice.

(See Principle 4; Rule 5.) 


\section{Chapter 4}

\section{PROVISIONS FOR EXCEPTIONS TO THE RULES AND FOR THE INTERPRE'TATION AND MODIFICATION OF RULES}

Provision 1. Modification and amendment of Rules. These Rules can be amended only by action of a plenary session of an International Congress for Microbiology convened by the International Association of Microbiologists.

Provision 2. Lists of nomina conservanda. To avoid disadvantageous changes in the nomenclature of the genera by the strict application of the Rules of Nomenclature, the Rules provide for a list of names which must be retained as exceptions (nomina conservanda).

Note 1. This list of conserved names will remain permanently open for additions. Any proposal of an additional name must be accompanied by a detailed statement of the case for and against its conservation. Such proposals must be submitted to the Judicial Commission (see Provision 4) for study and appropriate action.

Note 2. When a name proposed for conservation has been provisionally approved by the Judicial Commission, bacteriologists are authorized to retain it pending the decision of the next International Congress for Microbiology.

Note 3. A conserved name is conserved against all other names for the group, whether these are cited in the corresponding list of rejected names or not, so long as the group concerned is not united with another group bearing a legitimate name. In the event of union or reunion with another group, the earlier of the two competing names is adopted in accordance with Rules 19, 20, and 21 .

Note 4. A conserved name is conserved against all earlier homonyms.

Example: The generic name Bacillus Cohn with the type species B. subtilis Cohn em. Prazmowski is conserved by recommendation of the Nomenclature Committee and the action of the Second International Congress for Microbiology.

(See Principles 6, 9; Rule 24 (5), (6), (7).)

Provision 3. Lists of nomina rejicienda. To avoid unnecessary confusion in the nomenclature of bacteria by the strict application of the rules of nomenclature, the Rules provide a list of names (nomina rejicienda) which are not to be used, i.e. are to be permanently rejected. This list includes names which, owing to segregation, are used with different meanings and have become a permanent source of confusion or error (nomina ambigua), names where application is uncertain (nomina dubia), and names applied to a group made up of two or more discordant elements, especially if these elements were erroneously supposed to form part of the same individual (nomina confusa).

(See Principles 6, 9; Rule 24. (5), (6), (7).)

Note 1. This list of rejected names will remain permanently open for additions. Any proposal of an additional name must be accompanied by a detailed statement of the case for and against its rejection. Such proposals must be submitted to the Judicial Commission of the Nomenclature Committee for study and appropriate action. When a name proposed for rejection has been provisionally rejected by the Judicial Commission, bacteriologists are authorized to reject it pending the decision of the next International Congress for Microbiology.

Note 2. A rejected name may not be later introduced into bacteriological literature, except that nomina dubia may be removed from the list upon submission of evidence of correct status and by action by the Judicial Commission on Nomenclature.

Provision 4. Authorization of a Nomenclature Committee. A permanent Nomenclature Committee has been established by the International Association 
of Microbiologists in Congress. This Nomenclature Committee is so constituted that wherever practicable each nation is represented by at least one member, and no nation by more than five. Recommendations for nomination for membership on this Nomenclature Committee may be made by any society of microbiologists or by members of any International Congress. Recommendations for nominations should be made to one of the Permanent Secretaries who will present them to the Nomenclature Committee for consideration at its next meeting. Appointments to membership on the Nomenclature Committee are made by nomination by the Nomenclature Committee and election by the next following Plenary Session of an International Congress for Microbiology. The International Congress elects two Permanent Secretaries, one primarily to represent medical bacteriology and one to represent nonmedical bacteriology. The Nomenclature Committee shall elect such other officers as may be desired. A complete list of all members of the Nomenclature Committee shall be published in the Proceedings of each triennial meeting of the International Congress for Microbiology.

The Nomenclature Committee selects from its membership a Judicial Commission consisting of twelve members, exclusive of members ex officio, and designates a Chairman from the membership of the Commission. The two Permanent Secretaries of the Nomenclature Committee are members ex officio of the Judicial Commission. The commissioners serve in three classes of four commissioners each for nine years, so that one class of four commissioners retires at each International Congress. In the event of failure of the International Congress to meet triennially, the term of office of each class will automatically be extended by the number of years greater than three elapsing between successive Congresses. In case of resignation or death of any commissioner, his place shall be filled for the unexpired term by the Nomenclature Committee at its next meeting.

A. The Nomenclature Committee has the following functions:

(1) To consider and pass upon all recommendations relating to the formulation or modification of Rules of Nomenclature, particularly such rules as relate to bacteria, but also pertaining to nomenclature of other groups when desirable. The Committee will recommend such action as may be appropriate to the next Plenary Session of an International Congress for Microbiology.

(2) To consider all Opinions rendered by the Judicial Commission. Such Opinions become final if not rejected at the meeting of the International Committee next following the date on which the Opinion was issued.

(3) To designate official Type Culture Collections.

(4) To receive and act upon all reports and recommendations received from the Judicial Commission or other committees relating to problems of nomenclature or taxonomy.

(5) To hold at least one meeting triennially in connection with the meeting of the International Congress for Microbiology.

(6) To report to the final Plenary Session of each Congress a record of its actions, and to recommend for approval such actions and nominations as require the approval of the Congress. 
(7) To co-operate with other Committees, particularly those of the International Botanical and Zoological Congresses, to consider common problems of nomenclature.

(See General Considerations 1.)

B. The Judicial Commission of the Nomenclature Committee has the following functions:

(1) To issue formal 'Opinions' when asked to interpret rules of nomenclature in cases in which the application of a rule is doubtful.

(2) To prepare formal 'Opinions' relative to the status of names which have been proposed, placing such names when deemed necessary in special lists, such as lists of nomina conservanda, nomina rejicienda, etc.

(3) To develop recommendations for emendations of the International Rules for Bacteriological Nomenclature, for presentation to the Nomenclature Committee.

(4) To prepare formal 'Opinions' relative to types, particularly types of species and genera, and to develop a list of bacterial genera which have been proposed with the type species of each.

(5) To prepare and publish lists of names of genera which have been proposed for bacteria, for protozoa, or for other groups in which microbiologists are interested in order to assist authors of new names in avoiding invalid homonyms.

(6) To develop a list of publications in microbiology whose names of organisms shall have no standing in bacteriology in determination of priority.

(7) To edit and publish the International Rules of Bacteriological Nomenclature, Opinions, Lists of Nomina Conservanda, Nomina Rejicienda, Type Species, etc.

(8) To report to the Nomenclature Committee at its triennial meetings all Recommendations, Transactions, and Opinions.

(9) To report to the International Committee at its triennial meetings the names of all Commissioners whose terms of service expire, likewise a list of all vacancies caused by resignation or death.

(10) To prepare 'Opinions' when requested relative to the nomenclatural status of microorganisms studied by microbiological techniques, but not classed with the bacteria or viruses; for example, the yeasts, molds, and protozoa. However, such 'Opinions' shall not be issued until confirmed by the commission charged with the interpretation of the appropriate code of nomenclature (Botanical or Zoological).

Recommendation 4. Whenever, in the opinion of any microbiologist an interpretation of any rule or recommendation of nomenclature is desirable because the correct application of such a rule or recommendation is doubtful, or the stability of nomenclature could be increased by the conservation or by the rejection of some name which is a source of confusion or error, it is recommended that he prepare a résumé outlining the problem, citing pertinent references, and indicating reasons for and against specific interpretations. This résumé should be submitted to the Chairman of the Judicial Commission; if desired, through one of the Permanent Secretaries. An Opinion will be formulated, which may not be issued until it has been approved by at least eight members of the Commission.

(See Principles 2, 6.) 